\title{
ANOMALI SINYAL SEBELUM GEMPABUMI YANG TERDETEKSI OLEH REKAMAN SUPERCONDUCTING GRAVIMETER DAN SEISMOMETER (LHZ) (STUDI KASUS: GEMPABUMI DI INDONESIA MW > 6)
}

\author{
Mariska Natalia Rande ${ }^{1, a)}$, Mahmud Yusuf ${ }^{2, b)}$, Fajar Rachmadi Priyambada ${ }^{3, c)}$ \\ ${ }^{1}$ Sekolah Tinggi Meteorologi Klimatologi dan Geofisika Jakarta \\ ${ }^{2}$ Kedeputian InsKal dan Rekayasa Jaringan, BMKG Pusat \\ ${ }^{3}$ Balai Besar Meteorologi Klimatologi dan Geofisika Wilayah III - Denpasar
}

Email: ${ }^{a}$ mariskarande@gmail.com, b) mahmud.yusuuf@bmkg.go.id, ${ }^{\mathrm{c}}$ fajarrachmadi13@gmail.com

\begin{abstract}
Abstrak
Selain menimbulkan radiasi gelombang seismik, gempabumi juga menimbulkan perubahan distribusi massa bumi, yang menyebabkan perubahan nilai gayaberat yang kecil. Sebelum terjadi gempabumi signifikan, terkadang perubahan nilai gayaberat dapat terlihat. Kami menggunakan 1 Superconducting Gravimeter (SG) dan 2 Seismometer (LHZ) untuk meneliti gempabumi yang terjadi di Indonesia dengan $\mathrm{Mw} \geq 6$. Dilakukan reduksi nilai pasang surut pada rekaman SG untuk mendapatkan nilai gayaberat sebenarnya. Rekaman sinyal Seismometer (LHZ) masih berupa satuan kecepatan, yang selanjutnya diturunkan terhadap waktu untuk mendapatkan satuan percepatan yang sama dengan SG. Kemudian dengan menggunakan fungsi spektogram, kita dapat melihat distribusi frekuensi pada rekaman SG dan Seismometer (LHZ). Dari analisa spektogram pada rekaman SG didapatkan anomali < 24 jam sebelum terjadi gempabumi utama. Anomali tersebut memiliki frekuensi yang lebih rendah dari frekuensi gempa utama yaitu $\leq 0.2 \mathrm{~Hz}$ dan pada rekaman Seismometer (LHZ) tidak menunjukkan dengan jelas anomali sebelum terjadi gempabumi. Frekuensi ini berasosiasi dengan peningkatan gaya-gaya stres dari gempabumi utama sampai akhirnya pecah. Sehingga dapat disimpulkan bahwa SG dapat merekam anomali sebelum terjadi gempabumi utama yang signifikan.
\end{abstract}

Kata-kata kunci: Superconducting Gravimeter, Gempabumi, Prekursor.

\begin{abstract}
In addition to causing seismic wave radiation, earthquakes also cause changes in the distribution of the earth's mass, causing changes in small gravity values. Before a significant earthquake occurs, sometimes gravity changes can be seen. We used 1 Superconducting Gravimeter (SG) and 2 Seismometers (LHZ) to study earthquakes occurring in Indonesia with $\mathrm{Mw} \geq 6$. Tidal reduction values were made on $\mathrm{SG}$ recordings to obtain actual gravity values. The signal recording Seismometer (LHZ) is still a unit of speed, which is then downgraded to the time to get the same unit of acceleration as SG. Then by using the spectrograph function, we can see the frequency distribution on the SG and Seismometer (LHZ) recordings. From the spectrograph analysis on the SG recording, there was anomaly $<24$ hours before the major earthquake occurred. The anomaly has a frequency lower than the main quake frequency of $\leq 0.2$ $\mathrm{Hz}$ and on the recording Seismometer (LHZ) does not show clearly the anomaly before the earthquake occurred. This frequency is associated with an increase in stress forces from the main earthquake until it finally breaks out. So it can be concluded that SG can record anomalies before major major earthquakes occur.
\end{abstract}


Keywords: Superconducting Gravimeter, Earthquake, Precursor.

\section{PENDAHULUAN}

Berdasarkan penelitian sebelumnya Superconducting Gravimeter (SG) mampu merekam kejadian gempabumi lebih dulu dibanding seismometer, dikarenakan SG merupakan alat yang mengukur perubahan nilai gayaberat yang memiliki tingkat sensitivitas yang tinggi, keakuratannya mencapai $1 \mathrm{nGal}$ [2]. Akibat sensitivitas yang cukup tinggi, SG mampu merekam dinamika aktivitas kebumian dengan baik, seperti dinamika resonansi pada mantel bumi [5], efek hidrologi [7], Pasang surut bumi [1], hingga kejadian seismik baik yang mikroseismik maupun yang macroseismik [4], [6].

Pada Penelitian ini penulis menggunakan 1 SG yang terdapat di Cibinong dan dibandingkan dengan data pada 2 seismometer dari stasiun CBJI dan DBJI, untuk melihat anomali sebelum terjadinya gempabumi signifikan. Sehingga pada penelitian ini digunakan 2 gempabumi signifikan dengan jarak lokal hingga tele, yaitu gempa di Laut Bali (10 maret 2011) dan gempa di Selatan Pulau Jawa (03 April 2011). Tujuan dalam penelitian ini adalah mencari korelasi antara gangguan yang terekam oleh Superconducting Gravimeter (SG) pada kejadian gempabumi signifikan, yang kemudian dibuktikan dengan hasil perekaman seismometer. Hingga didapatkan anomali sebelum terjadinya gempabumi yang bervariasi hingga beberapa jam sebelum terjadinya gempabumi utama.

\section{METODE PENELITIAN}

Data yang digunakan pada penelitian ini adalah data gayaberat yang terekam oleh SG dan data rekaman seismometer dari CBJI dan DBJI. Dari data yang diambil di GFZ, didapatkan parameter sumber gempabumi (gambar 1 dan tabel 2). Paremeter stasiun dapat dilihat pada tabel 1.

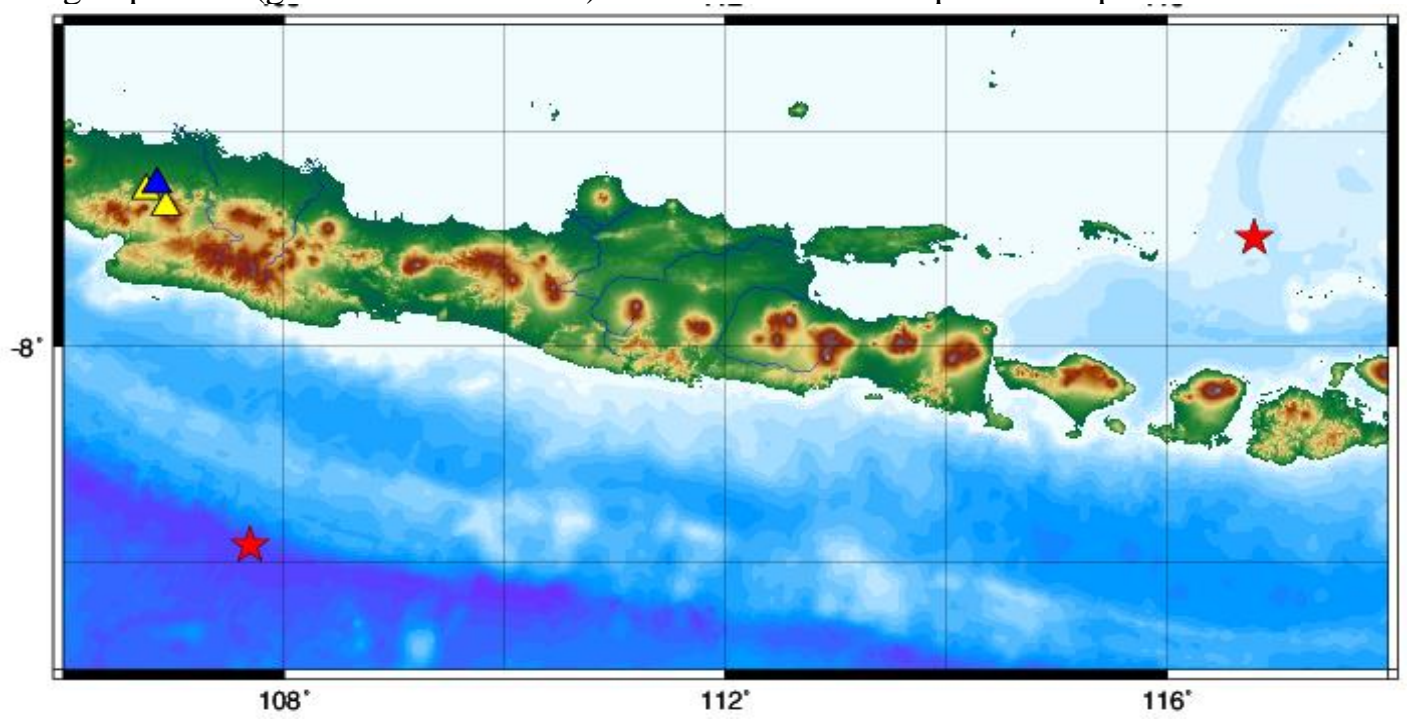

GAMBAR 1. Episenter gempabumi dan lokasi stasiun SG Cibinong, CBJI dan DBJI.

Dalam penelitian ini, diambil data satu hari sebelum terjadinya gempabumi utama, hingga beberapa jam setelah gempabumi utama. Pada data SG dilakukan pemisahan pengaruh dari pasang surut bumi sehingga didapatkan gayaberat sebenarnya dalam unit ugal. Sedangkan untuk data seismometer (LHZ), data diturunkan terhadap waktu terlebih dahulu. Hal ini dilakukan untuk menyamakan unit satuan ke dalam satuan percepatan, yakni ugal.

Kemudian dilakukan analisa spectrogram untuk melihat distribusi frekuensi yang disebabkan oleh gempabumi signifikan pada SG dan Seimometer. Spektrogram merupakan salah satu metode analisa spektral, dimana hasilnya memiliki domain time-frequency [3].

TABEL 1. Parameter stasiun SG Cibinong, CBJI dan DBJI 


\begin{tabular}{ccc}
\hline Stasiun & Lat & Lon \\
\hline SG Cibinong & -6.4903 & 106.8498 \\
CBJI & -6.7 & 106.93 \\
DBJI & -6.55 & 106.75 \\
\hline
\end{tabular}

TABEL 2. Parameter Gempabumi

\begin{tabular}{cccccc}
\hline Gempa & OT (UTC) & Lat & Lon & Mag & Ked (km) \\
\hline Jawa & $3 / 4 / 2011(20: 07: 35)$ & -9.85 & 107.69 & 6.7 & 14 \\
Bali & $10 / 3 / 2011(17: 10: 54)$ & -6.99 & 116.79 & 6.7 & 508 \\
\hline
\end{tabular}

HASIL DAN PEMBAHASAN

\section{Gempabumi di Jawa 3 April 2011}

Setelah dilakukan pemisahan nilai gayaberat dan pasang surut didapatkan nilai gayaberat sebenarnya dalam ugal seperti pada gambar 2a. untuk data pada seismometer CBJI dan DBJI diturunkan hingga mendapatkan nilai percepatan dalam satuan ugal seperti $2 \mathrm{~b}$ dan $2 \mathrm{c}$.

a)

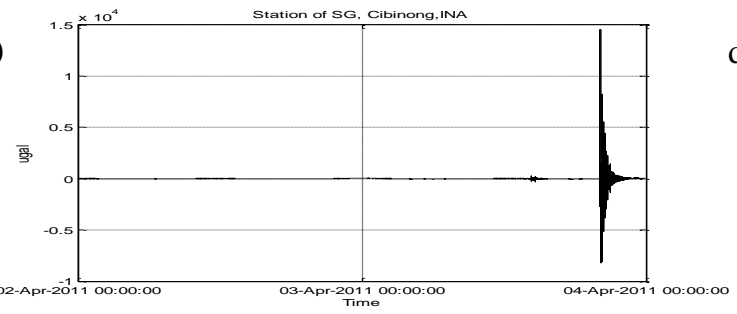

b)

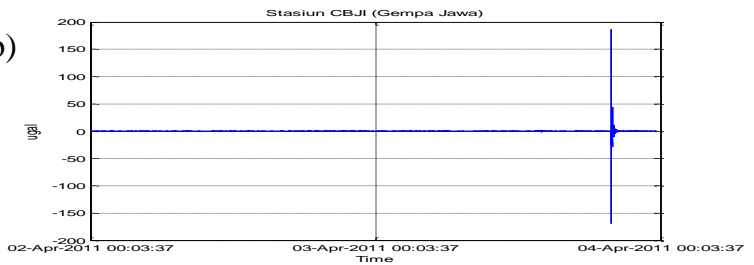

c)

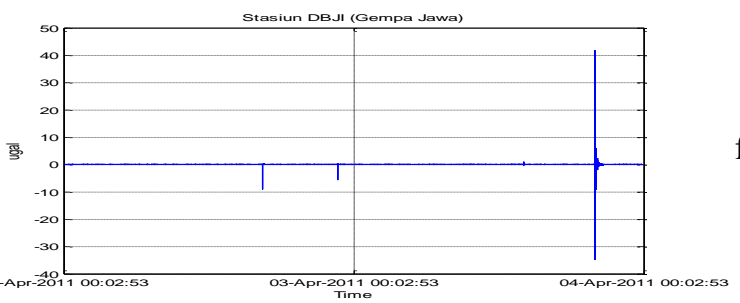

d)

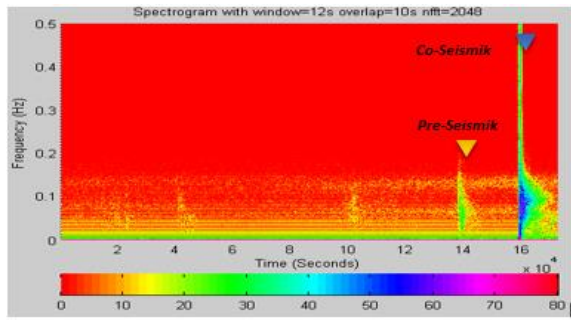

e)

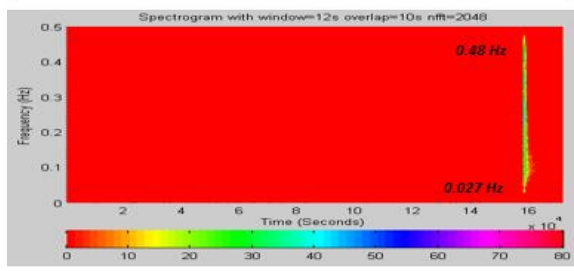

f)

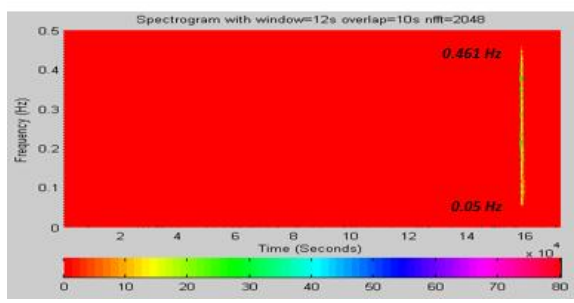

GAMBAR 2. Hasil rekaman SG dan seismometer untuk gempabumi di Jawa. a) residual gravity dari hasil rekaman SG; b) data rekaman seismometer CBJI; c) data rekaman seismometer DBJI; d), e) dan f) hasil analisa spektrogram dari gambar a, b dan c.

Pada gambar 2a, 2b dan 2c, menunjukkan SG merekam kejadian gempabumi lebih lama dibandingkan seismometer CBJI dan DBJI. Hal ini disebabkan SG menggunakan Helium (He) untuk mengganti fungsi pegas seperti yang terdapat pada gravimeter relatif lainnya, hal ini mengakibatkan 
SG memiliki tingkat sensitivitas yang tinggi. Ditinjau dari amplitudo maksimum, SG merekam gangguan akibat adanya gempabumi ini hingga 14550 ugal.

Hasil analisa spektrogram pada gambar $2 \mathrm{~d}, 2 \mathrm{e}$ dan $2 \mathrm{f}$ menunjukkan hasil rekaman dalam domain time-frequency. Didapatkan frekuensi untuk SG antara $0.01 \mathrm{~Hz}$ hingga $0.5 \mathrm{~Hz}$, sedangkan untuk seismometer CBJI dan DBJI masing-masing antara $0.027 \mathrm{~Hz}-0.48 \mathrm{~Hz}$ dan $0.05 \mathrm{~Hz}-0.461 \mathrm{~Hz}$. Selain mendapatkan nilai frekuensi dari masing-masing rekaman SG dan Seismometer, disini ditemukan sesuatu yang menarik sebelum terjadinya gempabumi, yaitu ditemukannya gangguan secara bersamaan beberapa jam sebelum terjadinya gempabumi. Rekaman ditunjukkan oleh SG dengan frekuensi antara $0.025 \mathrm{~Hz}$ hingga $0.14 \mathrm{~Hz}$, namun gangguan tersebut tidak terekam pada seismometer.

Anomali sebelum terjadinya gempabumi signifikan yang memiliki frekuensi tersebut berasosiasi dengan akumulasi stress gempabumi utama. Pada gempabumi di Jawa, anomali tersebut muncul 5 jam 49 menit 49 detik sebelum terjadinya gempabumi utama atau sekitar pukul 14:17:46 UTC.

\section{Gempabumi Laut Bali 10 Maret 2011}

Gempabumi yang berlokasi di laut Bali, memiliki jarak stasiun-episenter yang lebih jauh dibandingkan gempabumi di Jawa (Tabel 3) dan termasuk gempabumi dalam (Tabel 2). Setelah dilakukan pengolahan data SG dan Seismometer seperti pada kasus gempa di Jawa, maka d dapatkan nilai gayaberat pada SG dan nilai percepatan pada Seimometer, ditunjukkan pada gambar 3a, 3b dan $3 \mathrm{c}$ berikut.

a)

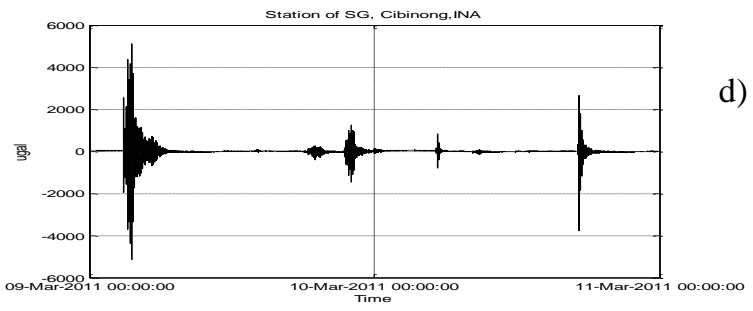

b)

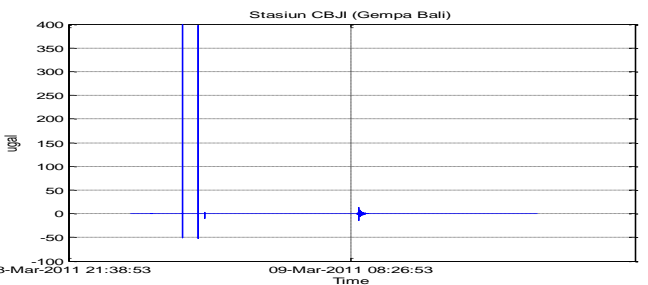

c)

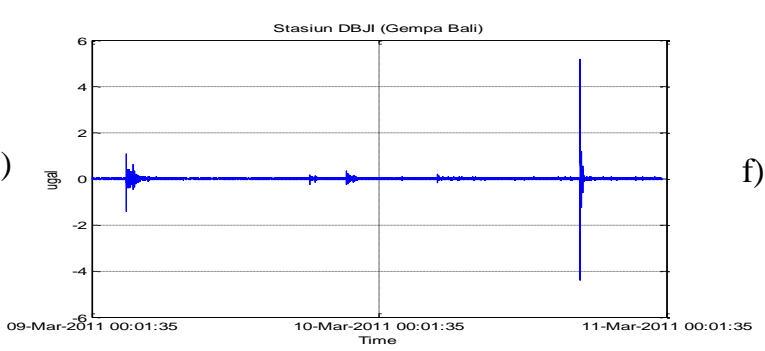

d)

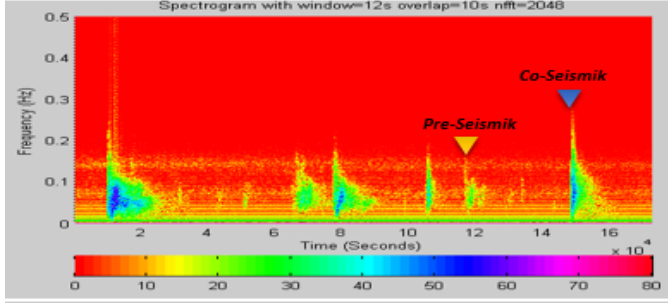

e)

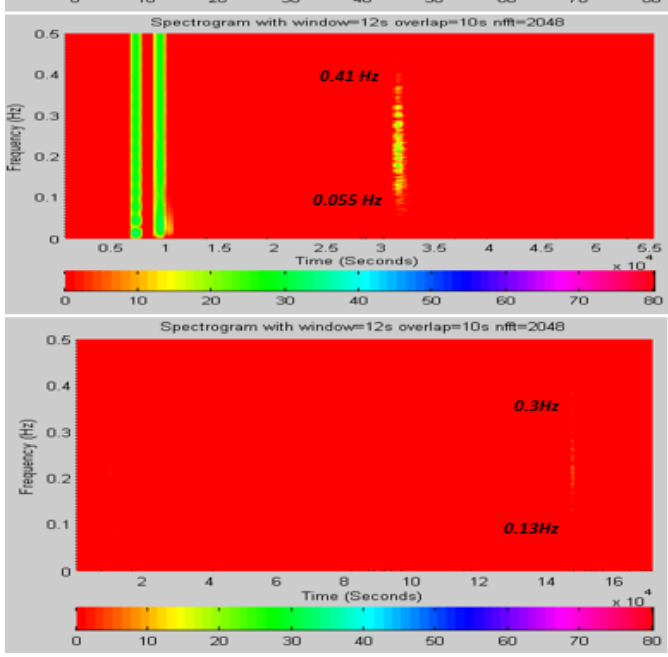

GAMBAR 3. Hasil rekaman SG dan seismometer untuk gempabumi laut Bali. a) residual gravity dari hasil rekaman SG; b) data rekaman seismometer CBJI; c) data rekaman seismometer DBJI; d), e) dan f) hasil analisa spektrogram dari gambar a, b dan c.

Seperti pada gempabumi di Jawa durasi gempabumi yang terekam pada SG lebih lama dibanding yang terekam pada Seimomeer (gambar 3a, 3b dan 3c) dan memiliki amplitudo maksimum hingga 3000 ugal. Hasil analisa spectrogram pada gambar 3d, 3e dan $3 \mathrm{f}$ menunjukkan hasil rekaman dalam domain time-frequency. Didapatkan frekuensi untuk SG antara $0.002 \mathrm{~Hz}$ hingga $0.28 \mathrm{~Hz}$, sedangkan 
untuk seismometer CBJI dan DBJI masing-masing antara $0.055 \mathrm{~Hz}-0.405 \mathrm{~Hz}$ dan $0.13 \mathrm{~Hz}-0.285$ Hz. Frekuensi gempabumi yang terekam pada Seismometer tidak begitu terlihat pada spekktogram, hal tersebut karena episenter gempa relatif jauh dan memiliki kedalaman yang dalam, sehingga terjadi atenuasi energi gempa. Dan juga ditemukan anomali beberapa jam sebelum terjadi gempabumi utama. Rekaman tersebut ditunjukkan oleh SG dengan frekuensi antara $0.02 \mathrm{~Hz}$ hingga $0.16 \mathrm{~Hz}$, namun gangguan tersebut tidak terekam pada seismometer. Anomali tersebut muncul 8 jam 52 menit 57 detik sebelum terjadinya gempabumi utama atau sekitar pukul 08:17:57 UTC.

TABEL 3. Jarak Episenter Gempabumi - SG Cibinong, CBJI dan DBJI.

\begin{tabular}{lcccc}
\hline \multirow{2}{*}{ Stasiun } & \multirow{2}{*}{ Lat } & Lon & \multicolumn{2}{c}{ Jarak episenter (derajat) } \\
\cline { 4 - 5 } & & & Gempa Jawa & $\begin{array}{c}\text { Gempa } \\
\text { Bali }\end{array}$ \\
\hline SG & -6.4903 & 106.8498 & 3.46 & 9.88 \\
Cibinong & -6.7 & 106.93 & 3.24 & 9.79 \\
CBJI & -6.55 & 106.75 & 3.43 & 9.98 \\
DBJI & &
\end{tabular}

\section{SIMPULAN}

Dari hasil Pengolahan data SG dan Seimometer pada kasus gempabumi di Jawa dan Bali, didapatkan bahwa SG mampu merekam gempabumi dengan durasi yang lebih lama dibandingkan Seismometer LHZ. Gangguan yang diakibatkan oleh gempabumi yang terekam oleh SG pada gempa Jawa dan Bali masing-masing 14550 ugal dan 3000 ugal.

Hasil analisa spektrogram untuk kedua gempabumi menunjukkan adanya anomali terjadinya gempabumi. Anomali tersebut ditunjukkan pada rekaman SG pada frekuensi $0.025 \mathrm{~Hz}$ hingga 0.14 $\mathrm{Hz}$ untuk gempa di Jawa dan $0.02 \mathrm{~Hz}$ hingga $0.16 \mathrm{~Hz}$ untuk gempa di Bali. Anomali pada frekuensi ini berasosiasi dengan akumulasi stress dari gempabumi utama. Sehingga dapat di simpulkan hasil rekaman SG sangat baik dan dapat dikembangkan lebih lanjut sebagai alat pendukung seismometer dalam monitoring gempabumi. Mengingat Indonesia memiliki tingkat seismisitas yang sangat tinggi.

\section{REFERENSI}

[1] Baldi, P., Casula, G., Focardi, S dan Palmonari, F, 1995, Tydal analisis of data recorded by a superconducting gravimeter, Annali di Geofisica, Vol XXXVIII.

[2] Hinderer, J., Crossley, D dan Warburton, R.J., 2007, Gravimetric Methods-Superconducting Gravity Meters. Elsevier B.V.

[3] Hippenstiel, R.D., 2002, Detection Theory: Application and Digital Signal Processing. CLC Press. Florida.

[4] Lan, S.C., Yu, T.T., Hwang, C dan Kao, R., 2011, An Analysis of Mechanical Constraints when Using Superconducting Gravimeters for Far-Field Pre Seismic Anomaly Detection. Terr. Atmos. Ocean. Sci., Vol. 22, No. 3, 271-282.

[5] Omerbashich, M., 2007, Magnification of Mantle Resonance as a cause of Tectonics, Geodinamica Acta (European Journal of Geodynamics) 20 (6), 369-383.

[6] Shen, W., Wang, D dan Hwang, C., 2011, Anomalous Signal Prior to Wenchuan Earthquake Detected by Superconducting Gravimeter and Broadband Seismometer Records. Journal of Earth Science, Vol. 22, no. 5, p. 640-651

[7] Virtanen, H., 2006, Studies of Earth Dynamics With the Superconducting Gravimeter, Acad. Disertation of Geophysic, University of Helsinki.

http://www.eas.slu.edu/GGP/ggphome.html

www.webdc.eu/webdc3/ 
